\title{
Comparative study of human neuronal and glial cell sensitivity for in vitro neurogenotoxicity testing
}

\author{
Blanca Laffon a, Natalia Fernández-Bertólez ${ }^{a}$, Carla Costa ${ }^{\text {b }}$, Eduardo Pásaro ${ }^{a}$, \\ Vanessa Valdiglesias ${ }^{\mathrm{a}, \mathrm{b}, *}$ \\ a Universidade da Coruña, DICOMOSA Group, Department of Psychology, Area of Psychobiology, Spain \\ ${ }^{\mathrm{b}}$ EPIUnit. Instituto de Saúde Pública, Universidade do Porto, Rua das Taipas, $n^{\circ} 135$, 4050-600 Porto, Portugal
}

\section{A R T I C L E I N F O}

\section{Article history:}

Received 29 December 2016

Received in revised form

1 February 2017

Accepted 3 February 2017

Available online 4 February 2017

\section{Keywords:}

A172 cells

Comet assay

Neurogenotoxicity

Micronucleus test

SH-SY5Y cells

$\gamma \mathrm{H} 2 \mathrm{AX}$ assay

\begin{abstract}
A B S T R A C T
Cell cultures from neuronal and glial origin have proven to be powerful tools for elucidating cellular and molecular mechanisms of nervous system development and physiology, and as neurotoxicity models to evaluate in vitro the possible effects of chemicals. But cellular heterogeneity of nervous system is considerable and these cells have been shown to respond diversely to neurotoxic insults, leading to disparate results from different studies. To shed more light on suitability of cellular models of nervous origin for neurotoxicity screening, the objective of this study was to compare the sensitivity to genetic damage induction of two nervous cell lines. To this aim, neurons (SH-SY5Y) and glial (A172) cells were treated with differently-acting genotoxic agents (bleomycin, actinomycin-D, methyl methanesulfonate, mitomycin C, and griseofulvin). After discarding cytotoxicity, genotoxicity was evaluated by a battery of assays encompassing detection of different genetic lesions. Results obtained showed that glial cells are generally more resistant to genotoxic damage induced by clastogenic agents, but more sensitive to aneugenic effects. These results highlight the need of proper design of in vitro neurotoxicology studies, especially for neurogenotoxicity screening, emphasizing the importance of employing more than one nervous cell type for testing the potential toxicity of a particular exposure.
\end{abstract}

() 2017 Published by Elsevier Ltd.

\section{Introduction}

In the last decades, several in vitro methods have been standardized and validated to replace or reduce some in vivo tests, since animal studies are expensive, require a considerable number of individuals and raise important ethical concerns (Carfi et al., 2007). However, in vitro neurotoxicity screening is not such advanced yet mainly due to the immense complexity and cellular heterogeneity of nervous system. Moreover, in vitro test systems currently available cannot be used to assess neurobiological functions such as cognition, motor coordination, sensory processing or integration (Coecke et al., 2006). Still, a number of biological processes that are general functional targets for neurotoxicants in vivo can be studied using in vitro systems, including morphological changes such as size and shape of cell body, neurite outgrowth, myelin formation, or metabolic and genomic alterations (Bal-Price et al., 2010; Tiffany-

\footnotetext{
* Corresponding author. Universidade da Coruña, Research Services Building, Campus Elviña s/n, 15071-A Coruña, Spain.

E-mail address: vvaldiglesias@udc.es (V. Valdiglesias).
}

Castiglioni, 2004). Hence, in vitro studies provide an understanding of the molecular/cellular mechanisms potentially involved in neurotoxicity, and, consequently, are ordinarily accepted and considered complementary to animal tests.

There are several in vitro models commonly used to test neurotoxicity (stem cells, primary cultures, brain slices ...) but cell lines have a number of advantages that make them very suitable to carry out neurotoxicological studies (reviewed in Banker and Goslin, 1998). Neuronal systems include diverse cell types among which perhaps not only one but several may be ideal for a particular experiment. In order to obtain valuable results, the specific culture system to be employed in neurotoxicity screening must be carefully selected on the basis of the cellular problem to be addressed and the own biological and developmental features of the candidate cells (reviewed in Hollenbeck and Bamburg, 2003). A172 glioblastoma cell line and SH-SY5Y neuroblastoma cell line are salient examples of such cell lines of human origin that have been routinely used in in vitro studies to elucidate basic neurobiological principles and mechanism of chemical action.

A172 is an astrocytoma non-tumorigenic cell line derived from a 
human glioblastoma that has been previously used in testing neurotoxicity as a glial model (Choi et al., 2004; Davis et al., 2002; de Ridder et al., 1987; Stark et al., 1992). SH-SY5Y is a neuroblastoma cell line extensively used as an in vitro neuronal model for the exploration of toxic cellular mechanisms and neurotoxin screening (Coleman et al., 2002). These neuronal cells present the capability of proliferating in culture for long periods without contamination, a prerequisite for the development of an in vitro cell model, and possess many biochemical and functional features of neurons even though, due to their immature neoplastic neural crest origin, they preserve properties of stem cells (Xie et al., 2010). These two cell lines model the basic cell types of the human central nervous system, astrocytes and neurons. However, due to their different properties and functions in the nervous system - neuronal cells are in close contact with astroglial cells (neuroglia, which make up about half the brain), which are considered as supporting cells for neurons (Allen et al., 2013) -, they are expected to respond differently against external insults.

On this basis, the main objective of the present study was to compare the different sensitivity to genetic damage induction of two cellular models commonly employed for in vitro neurotoxicity screening. To achieve this aim, neurons (SH-SY5Y) and glial (A172 astrocytes) cells were treated with a set of well-known differently acting genotoxic agents (i.e. bleomycin [BLM], actinomycin-D [ActD], methyl methanesulfonate [MMS], mitomycin $C$ [MMC], and griseofulvin [GF]). After discarding cytotoxicity by means of 3-(4,5dimethylthiazol-2-yl)-2,5-diphenyl tetrazolium bromide (MTT) assay, genotoxicity induced by these compounds was evaluated in neuronal and glial cells by a battery of assays encompassing detection of a range of genetic lesions, namely comet assay, $\gamma \mathrm{H} 2 \mathrm{AX}$ analysis, and micronucleus (MN) test.

\section{Materials and methods}

\subsection{Chemicals}

BLM (CAS No. 11056-06-7), Act-D (CAS No. 50-76-0), MMS (CAS No. 66-27-3), MMC (CAS No. 50-07-7), GF (CAS No. 126-07-8), MTT (CAS No. 298-93-1), RNase A, and propidium iodide (PI) were purchased from Sigma-Aldrich Co. BLM, MMS, MMC, and Act-D were dissolved in sterile distilled water $\left(\mathrm{dH}_{2} \mathrm{O}\right)$, and $\mathrm{GF}$ was dissolved in dimethyl sulfoxide (DMSO) (CAS No. 67-68-5) from Sigma-Aldrich Co.

\subsection{Cell culture}

Human neuroblastoma SH-SY5Y and human glioblastoma A172 cell lines were obtained from the European Collection of Cell Cultures. SH-SY5Y cells were cultured in nutrient mixture EMEM/ F12 (1:1) medium with $1 \%$ non-essential aminoacids, $1 \%$ antibiotic and antimycotic solution, and supplemented with $10 \%$ heatinactivated foetal bovine serum (FBS). Culture medium of A172 cell line consisted of DMEM (high glucose) with $2 \mathrm{mM} \mathrm{L}-$ glutamine, $1 \%$ antibiotic and antimycotic solution, and 10\% FBS. Cells were incubated in a humidified atmosphere with $5 \% \mathrm{CO}_{2}$ at $37{ }^{\circ} \mathrm{C}$. To carry out the experiments, between $5 \times 10^{4}$ and $8 \times 10^{4}$ cells, depending on the approach employed, were seeded in 96-well plates (flat bottom) and allowed to adhere for $24 \mathrm{~h}$ at $37^{\circ} \mathrm{C}$.

\subsection{Treatments}

To carry out the treatments, cells were exposed for $3 \mathrm{~h}$ at $37{ }^{\circ} \mathrm{C}$ with the specific genotoxic agent at four different concentrations ( $1 \%$ of final volume). The negative control used for BLM, MMS, MMC, and Act-D experiments was $\mathrm{dH}_{2} \mathrm{O}$, whereas DMSO was employed as negative control for GF experiments. The chemicals used, their respective concentrations, as well as the treatment time, were selected on the basis of previous studies (Garriott et al., 2002; Luukkonen et al., 2011; Wolff et al., 1999). Triton X-100 (1\%) was used as positive control for viability assays.

\subsection{Cellular viability}

MTT assay was performed according to Mosmann (1983) in order to evaluate the effects of the different compounds on SH-SY5Y and A172 cell viability and choose the concentrations for the genotoxicity tests. A total of 11 concentrations were employed in each case: BLM $(0.1-100 \mu \mathrm{g} / \mathrm{ml}$; i.e. $0.07-70 \mu \mathrm{M})$, Act-D $(0.01-100 \mu \mathrm{g} /$ $\mathrm{ml}$; i.e. $0.01-80 \mu \mathrm{M})$, MMS $(1-300 \mu \mathrm{g} / \mathrm{ml}$; i.e. $0.01-2.7 \mathrm{mM})$, MMC $(0.05-100 \mu \mathrm{g} / \mathrm{ml}$; i.e. $0.1-300 \mu \mathrm{M})$, and GF $(0.5-300 \mu \mathrm{g} / \mathrm{ml}$; i.e. 1.5-850 $\mu \mathrm{M})$. Briefly, after exposure, treatment solutions were removed, cells were washed with PBS twice, $100 \mu \mathrm{l}$ of MTT dye $(500 \mu \mathrm{g} / \mathrm{ml})$ dissolved in serum free medium were added to each well, and the plate was incubated at $37^{\circ} \mathrm{C}$ for $4 \mathrm{~h}$ (protected from light). At the end of this period, MTT solution was removed and $200 \mu \mathrm{l}$ of DMSO were added. For complete dissolution of purple formazan crystals, content of each well was quickly resuspended and the plate was kept away from light for an additional period of 5-10 min. Absorbance was measured at $570 \mathrm{~nm}$ using a SPECTROSTAR Nano microplate reader (BMG Labtech).

\subsection{Comet assay}

After treatments with the different compounds, the alkaline comet assay was performed following the general protocol proposed by Singh et al. (1988), with minor changes. Briefly, after collecting cells by trypsinization at $0.05 \%$, they were suspended in $80 \mu \mathrm{l}$ of low-melting-point agarose (LMA) at $0.7 \%$ in PBS (pH 7.4) Cells were then dropped onto a slide (two drops/slide) previously pre-coated with $1 \%$ normal-melting-point agarose in PBS, covered with coverslips and placed on ice for $10 \mathrm{~min}$ to allow agarose solidification. Coverslips were then removed and slides were carefully immersed in lysing solution (2.5 M NaCl, $100 \mathrm{mM} \mathrm{Na} 2$ EDTA, $10 \mathrm{mM}$ Tris- $\mathrm{HCl}, \mathrm{pH} 10$, with $1 \%$ Triton $\mathrm{X}-100$ added just before use) and left overnight at $4{ }^{\circ} \mathrm{C}$ in the dark. All steps after lysis were conducted under dim light to prevent the occurrence of additional DNA damage. Slides were placed in a horizontal gel electrophoresis tank with alkaline solution ( $1 \mathrm{mM} \mathrm{Na}{ }_{2}$ EDTA, $300 \mathrm{mM} \mathrm{NaOH}, \mathrm{pH}>13$ ) into an ice bath, and they were left for 40 min to allow DNA unwinding and alkali-labile site expression. Electrophoresis was carried out for $30 \mathrm{~min}$ at $25 \mathrm{~V}$ and $300 \mathrm{~mA}(0.71 \mathrm{~V} / \mathrm{cm})$. After electrophoresis, slides were rinsed three times for 5 min each with neutralising solution ( $0.4 \mathrm{M}$ Tris $-\mathrm{HCl}, \mathrm{pH} 7.5)$, left to air-dry in the dark, and stained with $40 \mu \mathrm{l}$ of $5 \mu \mathrm{g} / \mathrm{ml}$ 4,6-diamidino-2phenylindole (DAPI) in antifade solution, and covered with a coverslip. The preparations were kept in a humidified sealed box to prevent drying of the gel and analysed within $48 \mathrm{~h}$ to avoid excessive diffusion of the DNA in the gel. Image capture and analysis were performed using the Comet IV Software (Perceptive Instruments). In all cases 50 cells were scored from each replica (i.e. 100 cells in total), and percentage of DNA in the comet tail (\%tDNA) was used as DNA damage parameter.

\section{6. $\gamma H 2 A X$ analysis}

$\gamma \mathrm{H} 2 \mathrm{AX}$ analysis was conducted following the protocol described by Tanaka et al. (2009), with some modifications (Valdiglesias et al., 2011). The flow cytometry analysis was performed in a FACSCalibur flow cytometer (Becton Dickinson). Cell populations were gated according to size (forward scattering) and complexity (side 
scattering). A minimum of 10,000 events in the cell region were acquired, obtaining data from FL1 ( $\gamma \mathrm{H} 2 \mathrm{AX}$-Alexa Fluor 488) and FL2 (propidium iodide, PI) detectors. Data were analysed using Cell Quest Pro software (Becton Dickinson); the percentage of gated cells positive for both $\gamma \mathrm{H} 2 \mathrm{AX}$ and PI were calculated with regard to the total cells gated.

\subsection{Micronucleus evaluation by flow cytometry}

After $3 \mathrm{~h}$ treatments in the presence of BLM, Act-D, MMS, MMC or GF, cells were cultured in fresh medium for an additional period of $24 \mathrm{~h}$ (SH-SY5Ycells) or $48 \mathrm{~h}$ (A172 cells), adjusted according to each cell cycle duration. Subsequently, a suspension of nuclei and MN was prepared as previously described (Valdiglesias et al., 2011). The final suspension was analysed with a FACSCalibur flow cytometer (Becton Dickinson) employing Cell Quest Pro software (Becton Dickinson) for data analysis. For each sample, at a minimum, 50,000 events were evaluated from the PI signal detected in the FL2 channel. The percentage of MN was calculated with regard to the total number of nucleus and MN gated.

\subsection{Statistical analysis}

A minimum of three independent experiments were performed for each experimental condition tested, and each experiment was performed in duplicate. Experimental data were expressed as mean \pm standard error. Differences among groups were tested with Kruskal-Wallis test and Mann-Whitney $U$ test, whereas Spearman's correlation was employed to analyse the possible associations between two variables. A $p$ value $<0.05$ was considered significant. Statistical analyses were performed using SPSS for Windows statistical package (version 20.0).

\section{Results}

Prior to genotoxicity evaluation, MTT was carried out in neuronal and glial cells to check viability after exposure to a wide range of concentrations of BLM, Act-D, MMS, MMC and GF. BLM was found to induce dose-response decreases in viability of both cell types (A172: $\mathrm{r}=0.712 p<0.01$; SH-SY5Y: $\mathrm{r}=0.754, p<0.01$ ), although neurons resulted more sensitive than glial cells with statistically significant differences in viability from 2.5 to $10 \mu \mathrm{g} / \mathrm{ml}$ on, respectively (Fig. 1a). Similarly, treatment with MMS induced a dose-dependent decrease in viability of both $\mathrm{A} 172(\mathrm{r}=0.836$, $p<0.01)$ and SH-SY5Y $(\mathrm{r}=0.935, p<0.01)$ cells; these last ones were much more sensitive to MMS effects, with no living cells beyond $100 \mu \mathrm{g} / \mathrm{ml}$ (Fig. 1c). Act-D and MMC presented similar responses in the tested cells with slight effects on glial cells but relevant dose-dependent decreases in neuron viability after both Act-D ( $\mathrm{r}=0.710, p<0.01)$ (Fig. 1b) and MMC $(\mathrm{r}=0.748, p<0.01)$ (Fig. 1d) treatments. Opposite to the other compounds, GF induced more accused cytotoxicity in glial cells $(\mathrm{r}=0.773, p<0.01)$ as compared to neuron cells ( $r=0.471, p<0.01$ ) (Fig. 1e). From the results obtained in all these experiments, four different concentrations were selected in each case to perform the subsequent genotoxicity testing, i.e. $0.25,1,10$ and $50 \mu \mathrm{g} / \mathrm{ml}(0.2,0.7,7$ and $35 \mu \mathrm{M})$ for BLM; 0.01, 0.25, 5 and $25 \mu \mathrm{g} / \mathrm{ml}(0.01,0.2,4$ and $20 \mu \mathrm{M})$ for Act-D; 1, 2.5, 10 and $50 \mu \mathrm{g} / \mathrm{ml}(9,23,91$ and $450 \mu \mathrm{M})$ for MMS; $0.2,1.75,8.5$ and $35 \mu \mathrm{g} / \mathrm{ml}(0.6,5,24$ and $100 \mu \mathrm{M})$ for MMC, and 5, 15,50 and $100 \mu \mathrm{g} / \mathrm{ml}(14,43,142$ and $284 \mu \mathrm{M})$ for GF.

In order to evaluate the differences in responding to DNA damage induction, three different genotoxicity approaches, namely comet assay, $\gamma \mathrm{H} 2 \mathrm{AX}$ analysis and MN test, were carried out in neuronal and glial cells after being treated for $3 \mathrm{~h}$ with the different agents. Results obtained from these experiments are shown in
Figs. 2-6.

Increased values of primary DNA damage (A172: $r=0.716$, $p<0.01$; SH-SY5Y: $r=0.866, p<0.01$ ) (Fig. 2a) and $\gamma \mathrm{H} 2 \mathrm{AX}$ (A172: $\mathrm{r}=0.496, p<0.01$; SH-SY5Y: $\mathrm{r}=0.741, p<0.01$ ) (Fig. $2 \mathrm{~b}$ ) were observed in both cell types at all concentrations tested. Moreover, despite no MN production was observed in glial cells treated with BLM, this compound did induce increases in MN frequency in SHSY5Y cells $(\mathrm{r}=0.542, p<0.01)$, significant from $1 \mu \mathrm{g} / \mathrm{ml}$ concentration on (Fig. 2c.

Act-D caused similar concentration-dependent primary DNA damage in both cell types (A172: $r=0.874, p<0.01$; SH-SY5Y: $\mathrm{r}=0.822, p<0.01$ ) (Fig. 3a). However, minor effects were observed in phosphorylation of H2AX in glial cells treated with ActD while important levels of $\gamma \mathrm{H} 2 \mathrm{AX}$ were found in SH-SY5Y cells $(\mathrm{r}=0.520, p<0.01)$, particularly high at 0.25 and $5 \mu \mathrm{g} / \mathrm{ml}$ concentrations (Fig. 3b). Similarly, A172 cells showed slight increases in MN frequency just at 0.01 and $25 \mu \mathrm{g} / \mathrm{ml}$. On the contrary, a marked dose-dependent MN formation was observed in neuronal SH-SY5Y cells after treatments $(r=0.877, p<0.01)$ (Fig. 3c).

Important increases in primary DNA damage were found in A172 $(r=0.945, p<0.01)$ and SH-SY5Y $(r=0.896, p<0.01)$ cells (Fig. 4a). However, neither H2AX phosphorylation nor MN induction were observed in both cell types after MMS treatments, excepting a slight increase in neuronal cells treated with the highest concentration (Fig. 4b and c).

Treatments with MMC caused increases in primary DNA damage (Fig. 5a) and MN frequencies (Fig. 5c) in both cell lines tested, with positive dose-response relationships (\%tDNA: $\mathrm{r}=0.885, p<0.01$ in A172, and $\mathrm{r}=0.882, p<0.01$ in SH-SY5Y; \%MN: $\mathrm{r}=0.645, p<0.01$ in A172, and $r=0.757, p<0.01$ in SH-SY5Y). Nevertheless, only neuronal cells showed relevantly increased levels of phosphorylated H2AX (Fig. 5b).

In the case of GF, treatments with this compound induced primary DNA damage in A172 cells at the highest concentration and in SH-SY5Y from $15 \mu \mathrm{g} / \mathrm{ml}$ on (Fig. 6a), phosphorylation of H2AX in both cell types only at $100 \mu \mathrm{g} / \mathrm{ml}$, (Fig. 6b), and $\mathrm{MN}$ formation related to dose $(r=0.645, p<0.01)$ in A172 cells (Fig. $6 \mathrm{c}$ ).

\section{Discussion}

In vitro models are useful for the rapid screening of large numbers of agents regarding their potential to produce toxicity. Although cell cultures from neuronal origin are in some way limited since they do not reflect the complex physiology of the nervous system, they have proven to be powerful tools for elucidating cellular and molecular mechanisms of nervous system development and function, often predicting those observed in vivo (Ramabhadran et al., 2010). Cell cultures derived from nervous system are also frequently used to understand the mechanism of action of neurotoxic agents and to assess critical cellular events of neurodevelopment, including neural differentiation and neurite growth (Bal-Price et al., 2010). Thus, different cells of neural origin, including neurons, astrocytes, oligodendrocytes or microglial cells are commonly used as neurotoxicity models to evaluate in vitro the possible effects of chemicals and drugs to the cells and physiology of the nervous system. However, since they have different purpose in the organism, they are expected to respond to neurotoxic insults in a disparate way, making it difficult to establish the neurotoxic risk of one specific agent. Indeed, the diverse response of these cells against the same external insult (Coccini et al., 2015; Coleman et al., 2002), and also the different effects manifested regarding cells from other origins (e.g., hepatocytes, kidney cells, lymphocytes, skeletal muscle cells, etc.) (Rovetta et al., 2007; Valdiglesias et al., 2010) have been previously documented, supporting the relevance of employing particularly nervous system cell types for testing the 
a)

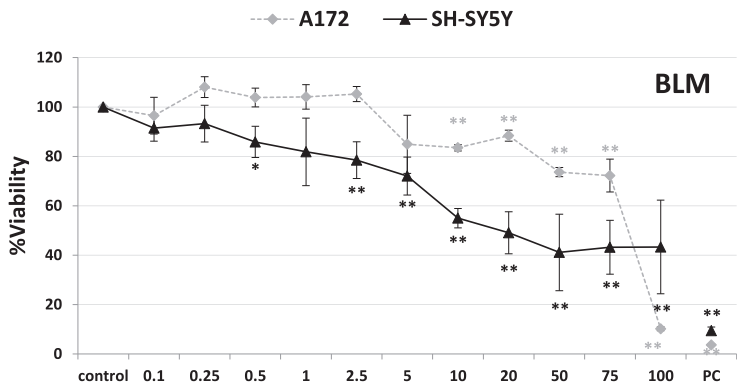

b)

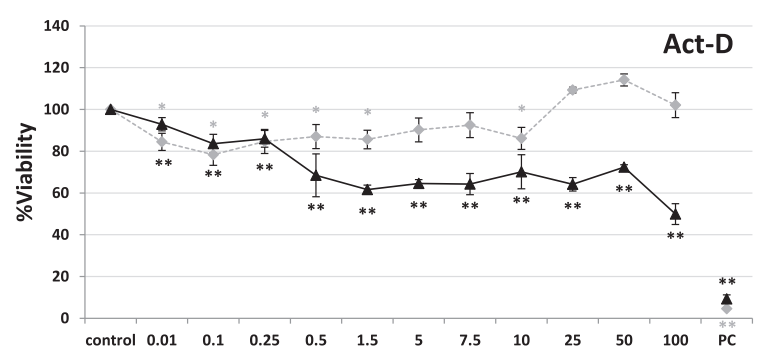

c)

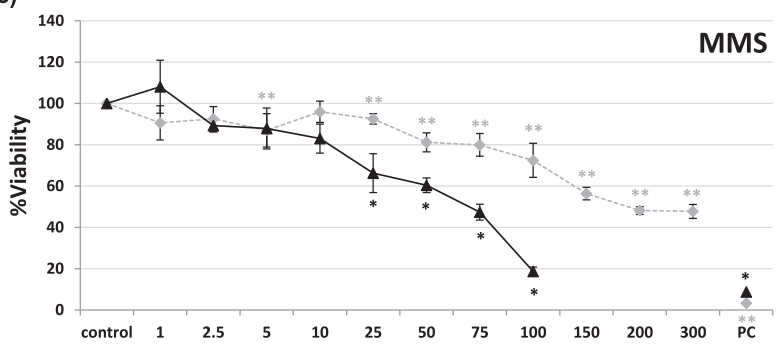

d)

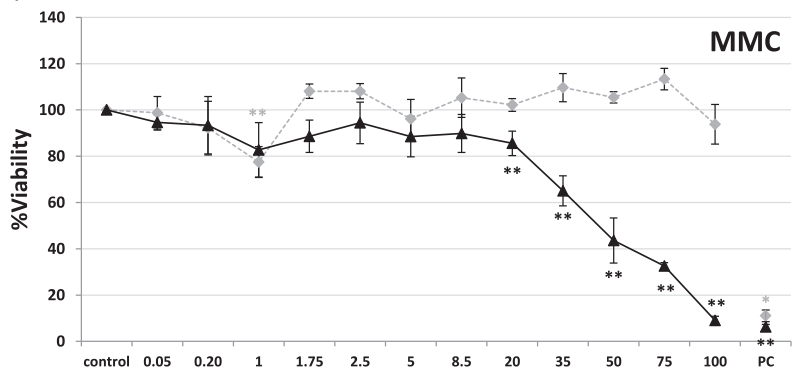

e)

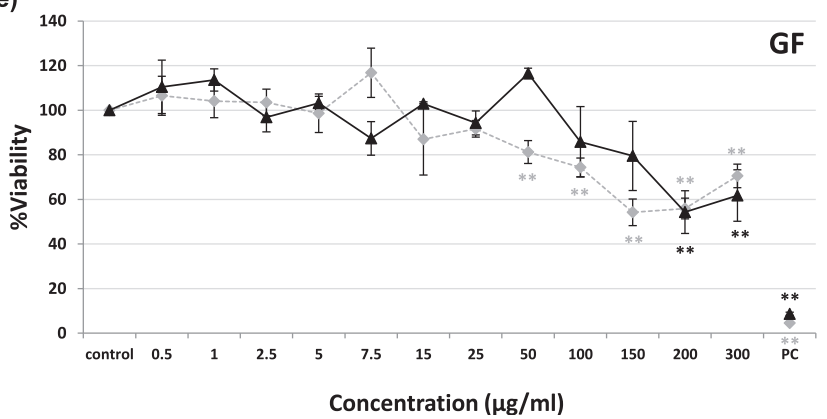

Fig. 1. Viability of glial and neuronal cells treated with BLM (a), Act-D (b), MMS (c) MMC (d) and GF (e), evaluated by MTT assay. Representative results from three independent experiments. ${ }^{* *} P<0.01 ;{ }^{*} P<0.05$, significant difference with regard to the negative control. PC: positive control.

toxicity of chemicals suspicious of being able to cross the bloodbrain barrier (e.g., nanomaterials). Moreover, most studies found in the literature employed just one of these cell types, restricting the neurotoxicity assessment perspective.

In the present study, two cell lines from human nervous system, gliomal A172 and neuroblastomal SH-SY5Y cells, were utilized in order to evaluate the different response of these cells to genetic damage induction. Considering that a distinction on whether a toxic agent affects neurons or glial cells is necessary in neurotoxicity screening, these cell lines were selected since both of them have been extensively used as neurotoxicity models and because they are from human origin, avoiding the need for interspecies extrapolation of results, which is not always straightforward.

MTT cytotoxicity assay was applied as an initial "screening" to compare the primary response of the different cells to the challenging agent, and to define the non-cytotoxic concentrations that would be later tested using genotoxicity specific endpoints. Results from these viability experiments showed that neurons are more sensitive to cytotoxic effects of agents tested in all cases excepting for GF, which induces similar cytotoxicity in both cell types. This

\section{$\square$ A172 $\square$ SH-SY5Y}
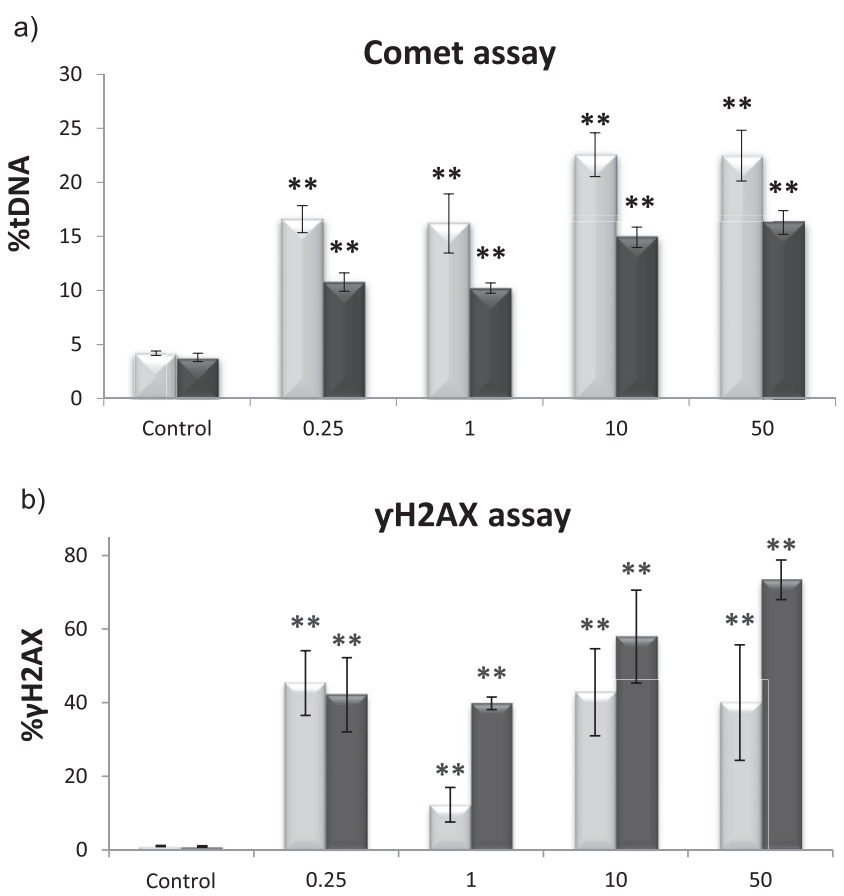

c)

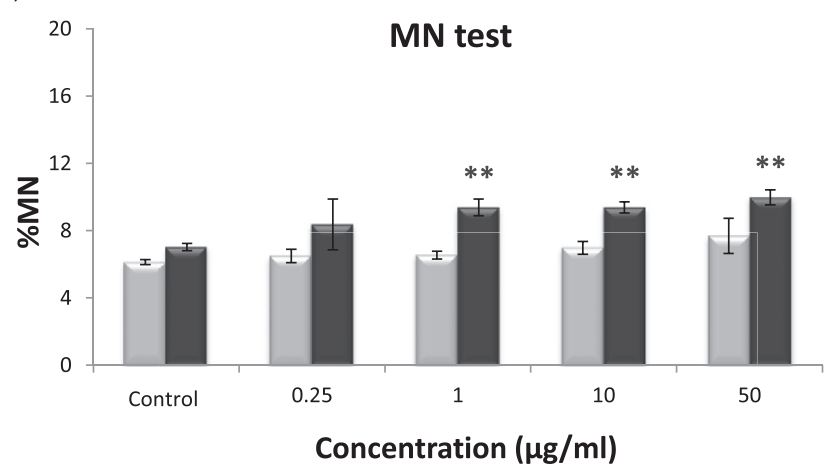

Fig. 2. Genotoxicity in glial and neuronal cells treated with BLM. Comet assay (a), $\gamma \mathrm{H} 2 \mathrm{AX}$ analysis (b), and MN frequency determined by flow cytometry (c). Representative results from three independent experiments. ${ }^{* *} P<0.01$, significant difference with regard to the corresponding control. 
Act-D

$\square$ A172 $\square$ SH-SY5Y

a)
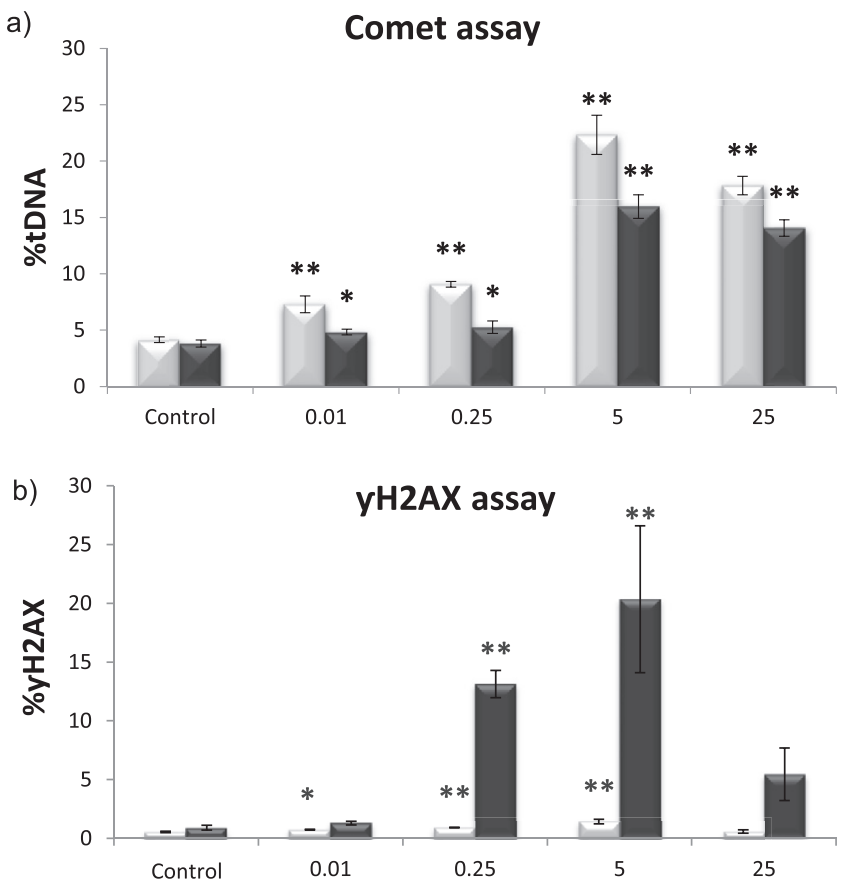

c)

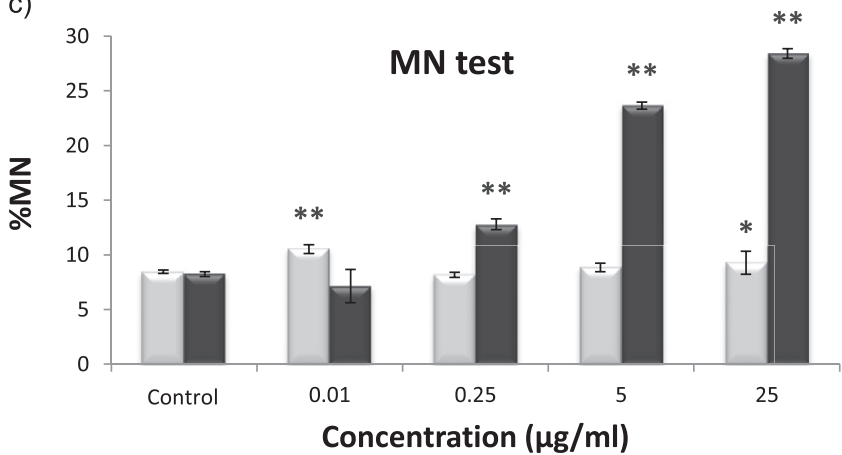

Fig. 3. Genotoxicity in glial and neuronal cells treated with Act-D. Comet assay (a), $\gamma \mathrm{H} 2 \mathrm{AX}$ analysis (b), and MN frequency determined by flow cytometry (c). Representative results from three independent experiments. ${ }^{*} P<0.05,{ }^{* *} P<0.01$, significant difference with regard to the corresponding control.

agrees with previous studies generally showing more sensitivity of neuronal cells to cytotoxicity induction as compared to glial cells (Coccini et al., 2015; Coleman et al., 2002; Rovetta et al., 2007). The relatively higher resistance of A172 cells to toxicity compared with the SH-SY5Y cells reflects to some extent the role of astrocytes in vivo. Astroglial cells are known to protect neuronal cells against stress conditions in vivo and in vitro (Saeed et al., 2015). On the basis of the results of MTT experiments, four concentrations were chosen in each case to perform the genotoxicity analysis, always considering a viability higher than $60 \%$ to avoid interference of cytotoxicity with the genotoxicity evaluation. Just one exception was made in the case of the highest concentration chosen for BLM $(50 \mu \mathrm{g} / \mathrm{ml})$, which was selected despite the low viability of SH-SY5Y cells (41\%) in order to make a proper comparison with A172 cells.

BLM is a well-known clastogenic agent, capable of inducing a wide spectrum of mutagenic lesions in mammalian cells, including DNA base damage, abasic sites, and alkali-labile sites (Chen and Stubbe, 2004; Milic and Kopjar, 2004; Povirk and Austin, 1991),

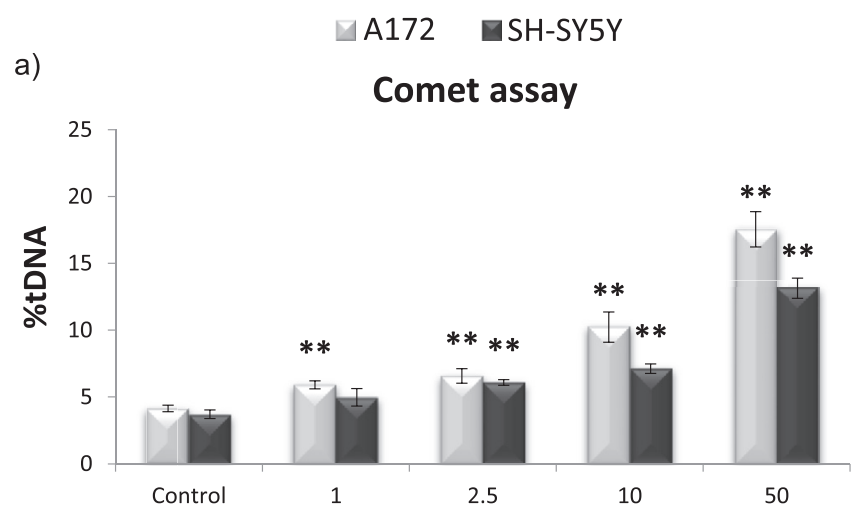

b)
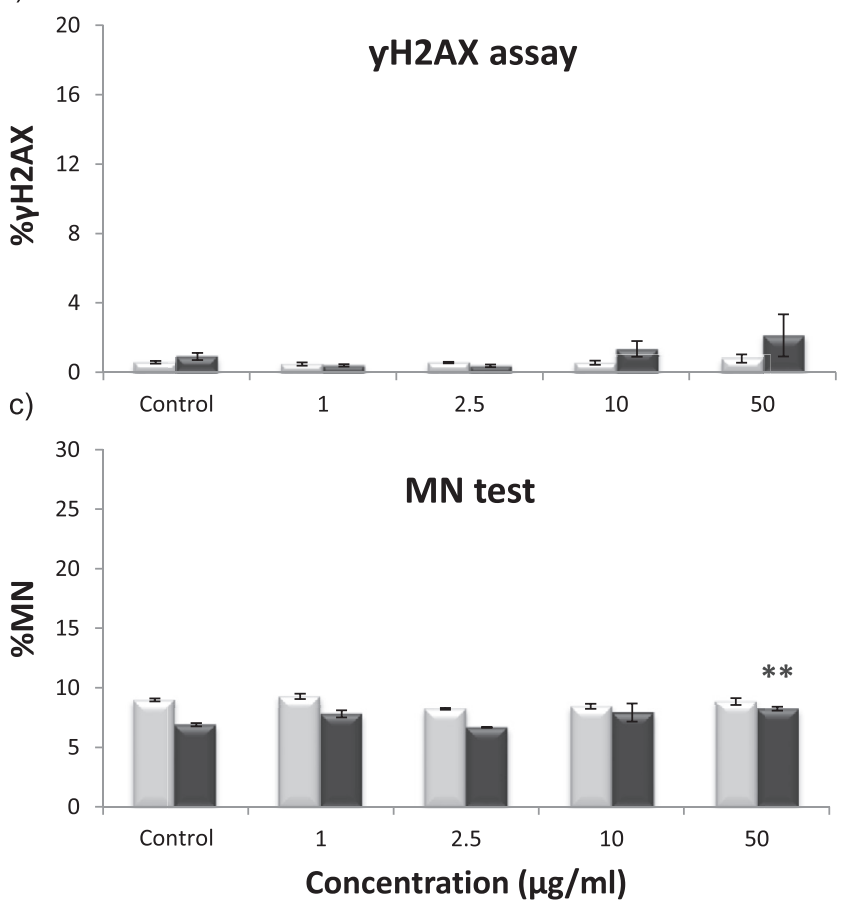

Fig. 4. Genotoxicity in glial and neuronal cells treated with MMS. Comet assay (a), $\gamma \mathrm{H} 2 \mathrm{AX}$ analysis (b), and MN frequency determined by flow cytometry (c). Representative results from three independent experiments. ${ }^{* *} P<0.01$, significant difference with regard to the corresponding control.

which eventually result in DNA single (SSBs) and double (DSBs) strand breaks. Consequently, it has been extensively used as DNA damage inductor and positive control in genotoxicity assays (Laffon et al., 2010; Mira et al., 2013; Valdiglesias et al., 2013a). From the MTT experiments, high sensitivity to BLM was observed in both SHSY5Y and A172 cells, especially pronounced in neurons, which resulted substantially affected from $0.5 \mu \mathrm{g} / \mathrm{ml}$ on. H2AX phosphorylation to generate $\gamma \mathrm{H} 2 \mathrm{AX}$ is an early indicator of DSB production, since this process is a signal for the recruitment of the different elements participating in DSB repair (Valdiglesias et al., 2013b). As for alkaline comet assay, it detects primary damage in the DNA - including SSBs, DSBs, alkali-labile sites and incomplete excision repair sites (Collins et al., 2014) -, and MN contain chromosome breaks or whole chromosomes lagged behind during anaphase, hence MN test reveals both clastogenic and aneugenic events (Fenech, 2008). As it was expectable due to its ability to generate DSBs and SSBs, significant dose-dependent increases in 
a)

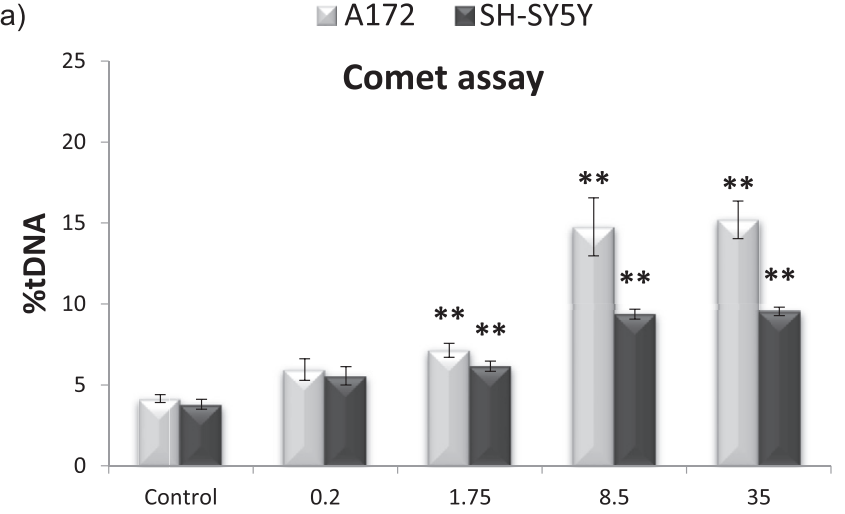

b)

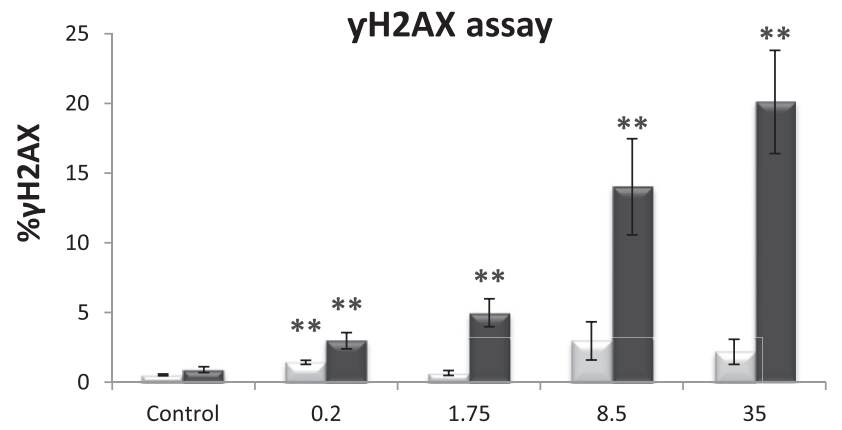

c)

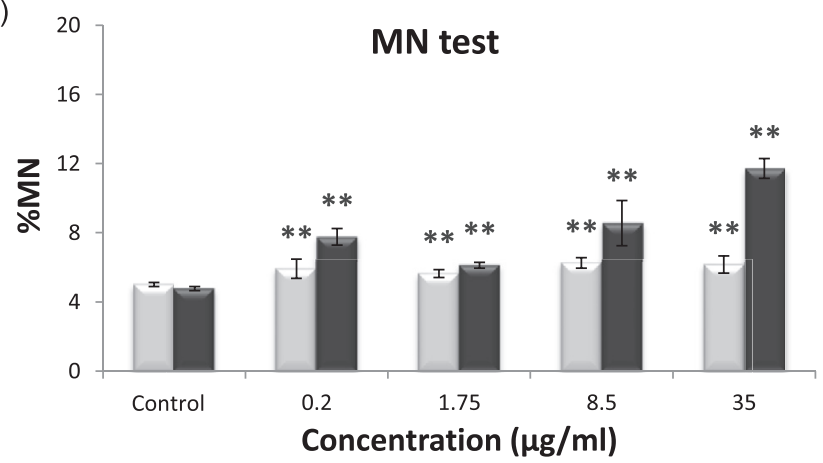

Fig. 5. Genotoxicity in glial and neuronal cells treated with MMC. Comet assay (a), $\gamma \mathrm{H} 2 \mathrm{AX}$ analysis (b), and MN frequency determined by flow cytometry (c). Representative results from three independent experiments. ${ }^{* *} P<0.01$, significant difference with regard to the corresponding control.

the percentage of $\gamma \mathrm{H} 2 \mathrm{AX}$ expression and in the \%tDNA were observed in both cell lines at all concentrations tested. However, although a dose-dependent increase in MN frequency was also obtained in neuronal cells, no induction of MN was found in astrocytes, indicating that these cells are able to repair the strand breaks initially induced by BLM and supporting the more marked sensitivity of neurons, which did fix that damage as chromosome alterations. Neurotoxic potential of BLM on neuronal and glial cells has been previously reported (Araki et al., 1998; Hosoi et al., 1998). Also, current results agreed with other previous experiments carried out in our laboratory, in which BLM $(1 \mu \mathrm{g} / \mathrm{ml})$ was employed as positive control for $\gamma \mathrm{H} 2 \mathrm{AX}$ analysis and comet assay in SH-SY5Y, inducing statistically significant notable increases in $\% \gamma \mathrm{H} 2 \mathrm{AX}$ and \%tDNA, respectively (Kiliç et al., 2016; Valdiglesias et al., 2010). Besides, this positive response was obtained regardless treatment time ( 3 or $24 \mathrm{~h}$ ) or culture medium conditions (with or without serum supplementation). In $\gamma \mathrm{H} 2 \mathrm{AX}$ experiments with A172 cells,
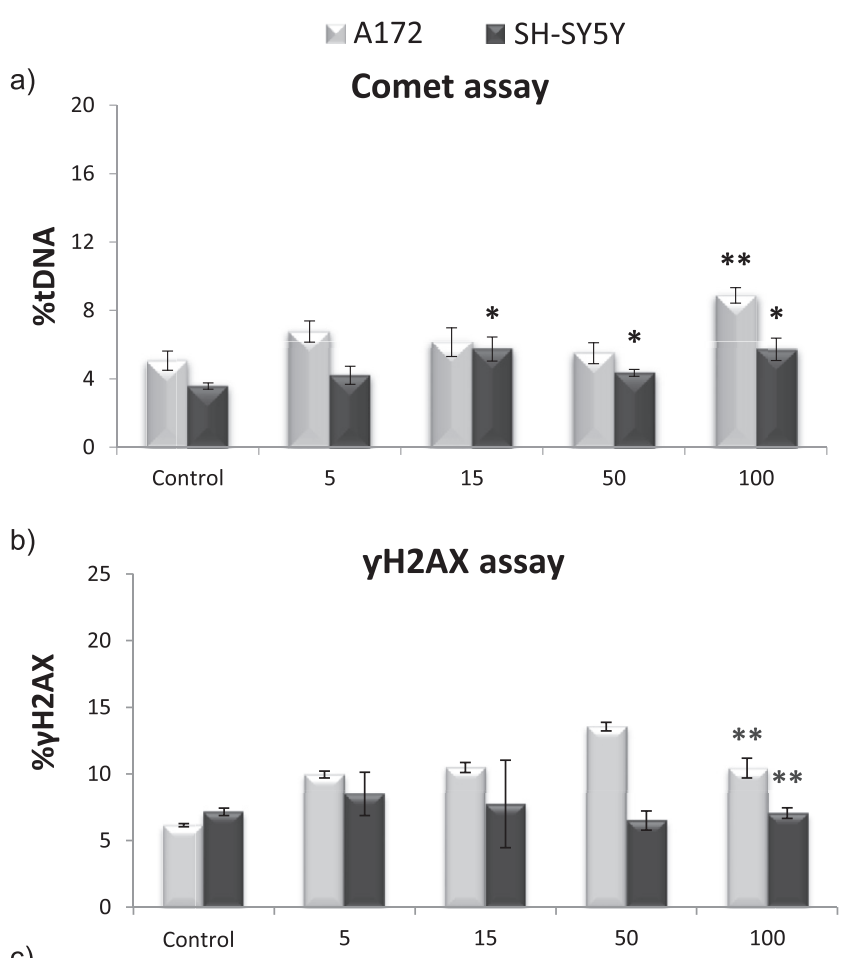

c)

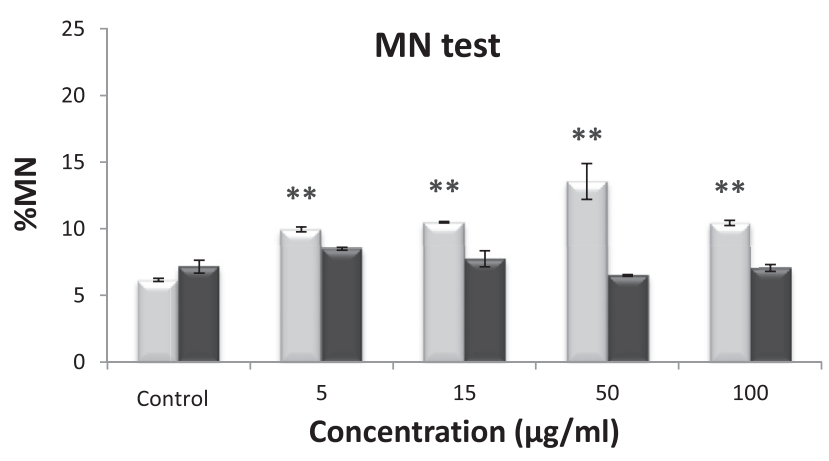

Fig. 6. Genotoxicity in glial and neuronal cells treated with GF. Comet assay (a), $\gamma \mathrm{H} 2 \mathrm{AX}$ analysis (b), and MN frequency determined by flow cytometry (c). Representative results from three independent experiments. ${ }^{*} P<0.05,{ }^{* *} P<0.01$, significant difference with regard to the corresponding control.

BLM was also found to induce relevant increases in DSB formation (unpublished results).

Act-D is an intercalating agent; it intercalates into DNA strands leading to DNA damage and inhibition of mRNA synthesis by interfering with RNA polymerase (Bensaude et al., 1999; Trask and Muller, 1988) and inducing both SSBs and DSBs (Mischo et al., 2005). In our study, no cytotoxic effects in A172 cells treated with this chemical were observed. Oppositely, low Act-D doses $(0.5 \mu \mathrm{g} /$ $\mathrm{ml}$ ) induced 30\% decrease in SH-SY5Y viability. Regarding genotoxicity, a significant dose-dependent increase in $\gamma \mathrm{H} 2 \mathrm{AX}$ levels and primary DNA damage was found in both cell lines. Phosphorylation of H2AX was especially noticeable in neuronal cells (20-fold increase at $5 \mu \mathrm{g} / \mathrm{ml}$ ). However, similarly to the response to BLM, the great majority of Act-D-induced damage was repaired by the glial cells avoiding MN formation, while in neurons it resulted in a dosedependent increase of chromosome alterations. Supporting our results, Act-D has been found to induce DNA damage in a number of studies employing other different cell lines and it is also commonly 
employed as positive control in genotoxicity assessment (Hashimoto et al., 2010; Porcedda et al., 2006; Sanchez-Flores et al., 2015). In a previous study with primary rat neurons, it was reported that cells remained alive and intact after $48 \mathrm{~h}$ of $0.1 \mu \mathrm{g} / \mathrm{ml}$ Act-D treatment (Martin et al., 1988). The authors explained these results in light of the fact that neurons could survive after 4-5 d of complete protein synthesis inhibition. Apart from this pioneer study, the information regarding neurotoxic effects of this compound is very scarce.

MMS is an alkylating compound which methylates DNA bases, usually guanine producing O6-methylguanine adducts, in a random manner (Ma et al., 2011). This causes SSBs that may lead to DSBs through either replication or repair processes (Zhou et al., 2006). Accordingly, MMS is another chemical usually employed as positive control in genotoxicity assays. Very high cytotoxic concentrationdependent damage was observed in both cells lines after MMS treatment, although it was especially extreme in the case of neuronal cells, with no surviving cells beyond $100 \mu \mathrm{g} / \mathrm{ml}$. However, despite these marked effects on viability, genetic damage induced in both SH-SY5Y and A172 cells resulted limited, with no effects observed in $\gamma \mathrm{H} 2 \mathrm{AX}$ levels or MN frequency, and just dosedependent increases in \%tDNA. According to the negative $\gamma \mathrm{H} 2 \mathrm{AX}$ and MN results, MMS clastogenic effect observed in comet assay is not related to DSB production and is repaired before cell division. Only a slight MN increase was obtained at the highest concentration in SHSY5Y cells, but it was probably due to the high cytotoxicity induced at this dose and therefore to the presence of apoptotic cells rather than chromosome fragmentation itself. In contrast to our results, Koyama et al. (2008) evaluated MMS effects on A172 cells and observed no decreases in viability after treatments with this compound up to $10 \mathrm{~h}$, but formation of apurinic/apyrimidinic sites after 2 and $4 \mathrm{~h}$; although concentration employed in their experiments was $1 \mu \mathrm{M}(0.11 \mu \mathrm{g} / \mathrm{ml})$, one order of magnitude below the lowest dose employed in the current study. In agreement with our findings, Sakuma et al. (2006) reported a time- and dosedependent increase of DNA strand breaks (evaluated by comet assay) in A172 cells treated with MMS $(2-20 \mu \mathrm{g} / \mathrm{ml})$. In neurons, Luukkonen et al. (2011) reported statistically significant decrease in viability and increase in primary DNA damage (comet assay) and MN frequency in SH-SY5Y cells after exposure to MMS (15-35 $\mu \mathrm{g} /$ $\mathrm{ml}$ ). And Kulkarni et al. (2008) reported viability results similar to those observed in the present study in differentiated SH-SY5Y cells treated with higher MMS doses (500-1500 $\mu \mathrm{M}$, equivalent to $55-165 \mu \mathrm{g} / \mathrm{ml}$ ) for $1 \mathrm{~h}$.

MMC is a potent antineoplastic drug that has been employed in chemotherapy of a number of cancers, including breast, lung, prostate, colorectal, and bladder cancer (Milic and Kopjar, 2004). It is also a well-known cross-linking substance extensively used as clastogenic agent and MN inducer in many in vitro and in vivo studies (Kataria et al., 2016; Nesti et al., 2000; Valdiglesias et al., 2011). No decrease in viability of glial cells was observed at any concentration tested, and significant decreases in neuronal viability were found only from $20 \mu \mathrm{g} / \mathrm{ml}$ on. Still, genetic damage was more noticeable, with positive responses in comet assay in both cell lines, and in H2AX phosphorylation in neuronal cells. Also MN frequencies resulted significantly higher after MMC treatments in both lines at all concentrations tested, suggesting that this compound causes DSBs eventually leading to chromosome alterations, but by different ways in neurons and in astrocytes according to the different results obtained under the same experimental conditions. In the case of glial cells, no marked positive response in $\gamma \mathrm{H} 2 \mathrm{AX}$ analysis (no relevant DSB induction), but clearly positive comet assay results (SSB and/or DSB production), suggest that MMC induced DSBs mainly indirectly, by causing SSBs which are transformed in DSBs after cell cycle progression, and then become MN.
Meanwhile in neuronal cells, MMC induced directly DSBs (both comet assay and $\gamma \mathrm{H} 2 \mathrm{AX}$ analysis positive) which were not able to be repaired and remained fixed as MN. Agreeing with our results, MMC $(0.08-1.28 \mu \mathrm{M})$ was previously found to induce concentration-dependent decrease in viability and increase in MN formation in primary cultured astrocytes from new-born male Sprague-Dawley rats (Miyakoshi et al., 1999). Also, MMC is frequently used in our laboratory as positive control for MN test. In previous studies in SH-SY5Y cells, this agent induced significant increases in MN frequency after 3 and $24 \mathrm{~h}$ treatments at $1.5 \mu \mathrm{M}$ $(0.5 \mu \mathrm{g} / \mathrm{ml})$ dose in both incomplete (serum-free) and complete culture media (Kiliç et al., 2016; Valdiglesias et al., 2011). Even so the same concentration was not enough to induce increases in MN frequency in A172 cells under the same experimental conditions, and a 10 -fold increase MMC concentration $(5 \mu \mathrm{g} / \mathrm{ml})$ was necessary to obtain a similar positive response in MN test (unpublished results).

GF is an aneugenic agent that interacts with the cell structure involved in chromosome segregation, probably by binding to microtubule-associated proteins and modifying the spindle of the dividing cell (Nesti et al., 2000; Wehland et al., 1977). Indeed, GF have been shown to induce aneuploidy in test systems ranging from in vitro cultured mammalian cells and somatic tissue of intact animals, to germ cells of rodents (Aardema et al., 1998). Differing from the results obtained for the other genotoxic agents employed in the present study, GF resulted less cytotoxic and genotoxic for neurons than for glial cells, with more accused decrease in viability, and dose-dependent increases in $\mathrm{MN}$ formation just observed in A172 cells. As aneugenicity caused by GF does not correlate with gene mutation or clastogenicity induction that results in chromosome aberrations via damage to DNA strands (Hashimoto et al., 2010), the slight positive effects observed in comet and $\gamma \mathrm{H} 2 \mathrm{AX}$ assays are likely due to cytotoxicity. To the best of our knowledge, there are no reports on GF neurogenotoxicity in the literature. Nevertheless, another similar aneugenic compound, vincristine, was observed to induce an important dose-dependent decrease in viability of glial A172 cells from $1 \mathrm{ng} / \mathrm{ml}$ on after a longer treatment (72 h) (Nakagawa et al., 2007).

\section{Conclusions}

The main problem in the development of a test strategy with predictive capacity for neurotoxicity is the complexity of the human nervous system (Bal-Price et al., 2010). For this main reason, selection of a particular nervous cellular in vitro system should be done in a careful way, considering that the different features of the cell types involved in nervous system physiology may determine diverse response against toxic insults. Results obtained in the present study support this need to carry out a correct in vitro neurotoxicology system selection, but also emphasize the importance of employing more than one nervous cell type for testing the potential toxicity of a particular exposure, especially in neurogenotoxicity screening, since neurons and astrocytes have been proved to respond diversely to genotoxicants.

Taking all results obtained from the five differently acting genotoxic agents together, it seems that glial cells are generally more resistant to cytotoxic and genotoxic damage induced by clastogenic agents, showing notable decreases in viability at lower doses of the challenging compounds and repair of DNA damage usually before it is fixed as chromosome aberrations; still they are more sensitive to aneugenic effects. In particular, SH-SY5Y resulted more sensitive than A172 cells to the effect of DNA binding (BLM) and intercalating (Act-D) agents; although they produce similar levels of strand breaks in both cell lines, milder in A172, this DNA damage could be efficiently repaired by glial cells but not by neuronal cells resulting 
in MN formation in this case. The opposite sensitivity was observed for aneugenic agents (GF), which only induced chromosome alterations in glial cells. Nevertheless, the response of both cell lines to the DNA damage induced by alkylating agents (MMS) and crosslinkers (MMC) was similar, with easily reparable genotoxic effects (limited to primary DNA damage) in the first case, but important genetic damage (DNA breaks and MN formation) in the second one.

The five compounds chosen to induce DNA damage, together with the different genotoxicity outcomes assessed, provide support to the view that nervous system cells have different sensitivity to genetic damage induction, as well as offer the basis to properly employ these approaches as neurotoxicity in vitro models for DNA damage evaluation.

\section{Acknowledgments}

Research funded by Xunta de Galicia (ED431B 2016/013). V. Valdiglesias was supported by a Xunta de Galicia postdoctoral fellowship (reference ED481B 2016/190-0).

\section{Transparency document}

Transparency document related to this article can be found online at http://dx.doi.org/10.1016/j.fct.2017.02.005.

\section{References}

Aardema, M.J., Albertini, S., Arni, P., Henderson, L.M., Kirsch-Volders, M. Mackay, J.M., Sarrif, A.M., Stringer, D.A., Taalman, R.D., 1998. Aneuploidy: a report of an ECETOC task force. Mutat. Res. 410, 3-79.

Allen, S.J., Watson, J.J., Shoemark, D.K., Barua, N.U., Patel, N.K., 2013. GDNF, NGF and BDNF as therapeutic options for neurodegeneration. Pharmacol. Ther. 138 $155-175$.

Araki, T., Enokido, Y., Inamura, N., Aizawa, S., Reed, J.C., Hatanaka, H., 1998. Changes in c-Jun but not Bcl-2 family proteins in p53-dependent apoptosis of mouse cerebellar granule neurons induced by DNA damaging agent bleomycin. Brain Res. 794, 239-247.

Bal-Price, A.K., Hogberg, H.T., Buzanska, L., Coecke, S., 2010. Relevance of in vitro neurotoxicity testing for regulatory requirements: challenges to be considered. Neurotoxicol Teratol. 32, 36-41.

Banker, G., Goslin, K., 1998. Culturing Nerve Cells, second ed. MIT Press, Cambridge.

Bensaude, O., Bonnet, F., Casse, C., Dubois, M.F., Nguyen, V.T., Palancade, B., 1999. Regulated phosphorylation of the RNA polymerase II C-terminal domain (CTD). Biochem. Cell Biol. 77, 249-255.

Carfi, M. Gennari, A., Malerba, I. Corsini, E., Pallardy, M., Pieters, R., Van Loveren, H. Vohr, H.W., Hartung, T., Gribaldo, L., 2007. In vitro tests to evaluate immunotoxicity: a preliminary study. Toxicology $229,11-22$.

Chen, J., Stubbe, J., 2004. Bleomycins: new methods will allow reinvestigation of old issues. Curr. Opin. Chem. Biol. 8, 175-181.

Choi, B.K., Choi, C.H., Oh, H.L., Kim, Y.K., 2004. Role of ERK activation in cisplatininduced apoptosis in A172 human glioma cells. Neurotoxicology 25, 915-924.

Coccini, T. Grandi, S. Lonati, D., Locatelli, C. De Simone, U., 2015. Comparative cellular toxicity of titanium dioxide nanoparticles on human astrocyte and neuronal cells after acute and prolonged exposure. Neurotoxicology 48, 77-89.

Coecke, S., Eskes, C., Gartlon, J., Kinsner, A., Price, A., van Vliet, E., Prieto, P. Boveri, M., Bremer, S., Adler, S., Pellizzer, C., Wendel, A., Hartung, T., 2006. The value of alternative testing for neurotoxicity in the context of regulatory needs. Environ. Toxicol. Pharmacol. 21, 153-167.

Coleman, M.D., O'Neil, J.D., Woehrling, E.K., Ndunge, O.B., Hill, E.J., Menache, A. Reiss, C.J., 2002. A preliminary investigation into the impact of a pesticide combination on human neuronal and glial cell lines in vitro. PLoS One 7, e42768.

Collins, A., Koppen, G., Valdiglesias, V., Dusinska, M., Kruszewski, M., Moller, P., Rojas, E., Dhawan, A., Benzie, I., Coskun, E., Moretti, M., Speit, G., Bonassi, S., 2014. The comet assay as a tool for human biomonitoring studies: the ComNet project. Mutat. Res. Rev. Mutat. Res. 759, 27-39.

Davis, R.L., Dertien, J., Syapin, P.J., 2002. Ethanol-induced modulation of inducible nitric-oxide synthase activity in human A172 astrocytoma cells. Alcohol Clin. Exp. Res. 26, 1404-1411.

de Ridder, L.I., Laerum, O.D., Mork, S.J., Bigner, D.D., 1987. Invasiveness of human glioma cell lines in vitro: relation to tumorigenicity in athymic mice. Acta Neuropathol. 72, 207-213.

Fenech, M., 2008. The micronucleus assay determination of chromosomal level DNA damage. Methods Mol. Biol. 410, 185-216.

Garriott, M.L., Phelps, J.B., Hoffman, W.P., 2002. A protocol for the in vitro micronucleus test. I. Contributions to the development of a protocol suitable fo regulatory submissions from an examination of 16 chemicals with different mechanisms of action and different levels of activity. Mutat. Res. 517, 123-134.

Hashimoto, K., Nakajima, Y., Matsumura, S., Chatani, F., 2010. An in vitro micronucleus assay with size-classified micronucleus counting to discriminate aneugens from clastogens. Toxicol Vitro 24, 208-216.

Hollenbeck, P.J., Bamburg, J.R., 2003. Comparing the properties of neuronal culture systems: a shopping guide for the cell biologist. Methods Cell Biol. 71, 1-16.

Hosoi, Y., Miyachi, H., Matsumoto, Y., Ikehata, H., Komura, J., Ishii, K., Zhao, H.J., Yoshida, M., Takai, Y., Yamada, S., Suzuki, N., Ono, T., 1998. A phosphatidylinositol 3-kinase inhibitor wortmannin induces radioresistant DNA synthesis and sensitizes cells to bleomycin and ionizing radiation. Int. J. Cancer 78, 642-647.

Kataria, S.K., Chhillar, A.K., Kumar, A., Tomar, M., Malik, V., 2016. Cytogenetic and hematological alterations induced by acute oral exposure of imidacloprid in female mice. Drug Chem. Toxicol. 39, 59-65.

Kiliç, G. Costa, C., Fernández-Bertólez, N.. Pásaro, E., Teixeira, J.P. Laffon, B., Valdiglesias, V., 2016. In vitro toxicity evaluation of silica-coated iron oxide nanoparticles in human SHSY5Y neuronal cells. Toxicol. Res. 5, 235-247.

Koyama, S., Sakurai, T., Nakahara, T., Miyakoshi, J., 2008. Extremely low frequency (ELF) magnetic fields enhance chemically induced formation of apurinic/apyrimidinic (AP) sites in A172 cells. Int. J. Radiat. Biol. 84, 53-59.

Kulkarni, A., McNeill, D.R., Gleichmann, M., Mattson, M.P., Wilson 3rd, D.M., 2008. XRCC1 protects against the lethality of induced oxidative DNA damage in nondividing neural cells. Nucleic Acids Res. 36, 5111-5121.

Laffon, B., Valdiglesias, V., Pasaro, E., Mendez, J., 2010. The organic selenium compound selenomethionine modulates bleomycin-induced DNA damage and repair in human leukocytes. Biol. Trace Elem. Res. 133, 12-19.

Luukkonen, J., Liimatainen, A., Hoyto, A., Juutilainen, J., Naarala, J., 2011. Pre-exposure to $50 \mathrm{~Hz}$ magnetic fields modifies menadione-induced genotoxic effects in human SH-SY5Y neuroblastoma cells. PLoS One 6, e18021.

Ma, W., Westmoreland, J.W., Gordenin, D.A., Resnick, M.A., 2011. Alkylation base damage is converted into repairable double-strand breaks and complex intermediates in G2 cells lacking AP endonuclease. PLoS Genet. 7, e1002059.

Martin, D.P., Schmidt, R.E., DiStefano, P.S., Lowry, O.H., Carter, J.G., Johnson Jr., E.M., 1988. Inhibitors of protein synthesis and RNA synthesis prevent neuronal death caused by nerve growth factor deprivation. J. Cell Biol. 106, 829-844.

Milic, M., Kopjar, N., 2004. Evaluation of in vitro genotoxic activity of bleomycin and mitomycin C in human lymphocytes using the alkaline comet assay. Arh. Hig. Rada Toksikol. 55, 249-259.

Mira, A., Gili, J.A., Lopez-Larraza, D.M., 2013. The influence of nonprotein thiols on DNA damage induced by bleomycin in single human cells. J. Environ. Pathol. Toxicol. Oncol. 32, 219-228.

Mischo, H.E., Hemmerich, P., Grosse, F., Zhang, S., 2005. Actinomycin D induces histone gamma-H2AX foci and complex formation of gamma-H2AX with Ku70 and nuclear DNA helicase II. J. Biol. Chem. 280, 9586-9594.

Miyakoshi, Y., Suzuki, Y., Ooida, M., Takahashi, A., Tsukui, M., 1999. Micronucleus test using cultured new born rat astrocytes. Ind. Health 37, 95-102.

Mosmann, T., 1983. Rapid colorimetric assay for cellular growth and survival: application to proliferation and cytotoxicity assays. J. Immunol. Methods 65, $55-63$.

Nakagawa, T., Kubota, T., Ido, K., Sakuma, T., Matsuda, K., 2007. The combined effects of multiple chemotherapeutic agents for malignant glioma cells. J. Neurooncol $84,31-37$.

Nesti, C., Trippi, F., Scarpato, R., Migliore, L., Turchi, G., 2000. Cytokinesis-block micronucleus assay in primary human liver fibroblasts exposed to griseofulvin and mitomycin C. Mutagenesis 15, 143-147.

Porcedda, P., Turinetto, V., Lantelme, E., Fontanella, E., Chrzanowska, K., Ragona, R., De Marchi, M., Delia, D., Giachino, C., 2006. Impaired elimination of DNA double-strand break-containing lymphocytes in ataxia telangiectasia and Nijmegen breakage syndrome. DNA Repair (Amst) 5, 904-913.

Povirk, L.F., Austin, M.J., 1991. Genotoxicity of bleomycin. Mutat. Res. 257, 127-143.

Ramabhadran, R., Simmons, S.O., Mundy, W.R., 2010. Molecular approaches to identify specific modes of action for neurotoxicity in vitro. Neurotoxicology. In: Harry, G.J., Tilson, H.A. (Eds.), Neurotoxicology, third ed. Informa Healthcare USA, Inc., New York, pp. 1-28.

Rovetta, F., Catalani, S., Steimberg, N., Boniotti, J., Gilberti, M.E., Mariggio, M.A., Mazzoleni, G., 2007. Organ-specific manganese toxicity: a comparative in vitro study on five cellular models exposed to $\mathrm{MnCl}(2)$. Toxicol Vitro 21, 284-292.

Saeed, Y., Rehman, A., Xie, B., Xu, J., Hong. M. Hong, Q. Deng, Y., 2015. Astroglial U87 cells protect neuronal SH-SY5Y cells from indirect effect of radiation by reducing DNA damage and inhibiting fas mediated apoptotic pathway in coculture system. Neurochem. Res. 40, 1644-1654.

Sakuma, N., Komatsubara, Y., Takeda, H., Hirose, H., Sekijima, M., Nojima, T. Miyakoshi, J., 2006. DNA strand breaks are not induced in human cells exposed to $2.1425 \mathrm{GHz}$ band $\mathrm{CW}$ and W-CDMA modulated radiofrequency fields allocated to mobile radio base stations. Bioelectromagnetics 27, 51-57.

Sanchez-Flores, M., Pasaro, E., Bonassi, S., Laffon, B., Valdiglesias, V., 2015. gammaH2AX assay as DNA damage biomarker for human population studies: defining experimental conditions. Toxicol. Sci. 144, 406-413.

Singh, N.P., McCoy, M.T., Tice, R.R., Schneider, E.L., 1988. A simple technique for quantitation of low levels of DNA damage in individual cells. Exp. Cell Res. 175, 184-191.

Stark, M., Wolff, J.E., Korbmacher, A., 1992. Modulation of glial cell differentiation by exposure to lead and cadmium. Neurotoxicol Teratol. 14, 247-252.

Tanaka, T., Halicka, D., Traganos, F., Darzynkiewicz, Z., 2009. Cytometric analysis of 
DNA damage: phosphorylation of histone H2AX as a marker of DNA doublestrand breaks (DSBs). Methods Mol. Biol. 523, 161-168.

Tiffany-Castiglioni, E., 2004. In vitro neurotoxicology: introduction to concepts. In: Tiffany-Castiglioni, E. (Ed.), In Vitro Neurotoxicology Principles and Challenges. Humana Press, Totowa, New Jersey, pp. 1-28.

Trask, D.K., Muller, M.T., 1988. Stabilization of type I topoisomerase-DNA covalent complexes by actinomycin D. Proc. Natl. Acad. Sci. U. S. A. 85, 1417-1421.

Valdiglesias, V., Costa, C., Sharma, V., Kilic, G., Pasaro, E., Teixeira, J.P., Dhawan, A., Laffon, B., 2013a. Comparative study on effects of two different types of titanium dioxide nanoparticles on human neuronal cells. Food Chem. Toxicol. 57, $352-361$.

Valdiglesias, V., Giunta, S., Fenech, M., Neri, M., Bonassi, S., 2013b. gammaH2AX as a marker of DNA double strand breaks and genomic instability in human population studies. Mutat. Res. 753, 24-40.

Valdiglesias, V., Laffon, B., Pasaro, E., Mendez, J., 2011. Evaluation of okadaic acidinduced genotoxicity in human cells using the micronucleus test and
gammaH2AX analysis. J. Toxicol. Environ. Health A 74, 980-992.

Valdiglesias, V., Mendez, J. Pasaro, E., Cemeli, E., Anderson, D., Laffon, B., 2010. Assessment of okadaic acid effects on cytotoxicity, DNA damage and DNA repair n human cells. Mutat. Res. 689, 74-79.

Wehland, J., Herzog, W., Weber, K., 1977. Interaction of griseofulvin with microtubules, microtubule protein and tubulin. J. Mol. Biol. 111, 329-342.

Wolff, J.E., Trilling, T., Molenkamp, G., Egeler, R.M., Jurgens, H., 1999. Chemosensitivity of glioma cells in vitro: a meta analysis. J. Cancer Res. Clin. Oncol. $125,481-486$.

Xie, H.R., Hu, L.S., Li, G.Y., 2010. SH-SY5Y human neuroblastoma cell line: in vitro cell model of dopaminergic neurons in Parkinson's disease. Chin. Med. J. Engl. 123, 1086-1092.

Zhou, C., Li, Z., Diao, H., Yu, Y., Zhu, W., Dai, Y., Chen, F.F., Yang, J., 2006. DNA damage evaluated by gammaH2AX foci formation by a selective group of chemical/ physical stressors. Mutat. Res. 604, 8-18. 